\title{
$\mathrm{GC/MSD}$ 를 사용한 원유 내 잔류농약의 분석법 연구
}

\author{
오남수* · 신용국 · 백승천 \\ 서울우유 중앙연구소
}

\section{Research for the Analytical Method of Various Pesticides in Raw Milk by Gas Chromatography-Mass Spectrometry}

\author{
N. S. Oh*, Y. K. Shin, and S. C. Baick \\ Institute of Dairy Food Research, Seoul Dairy Cooperative, Ansan 425-838, Korea
}

\begin{abstract}
The aim of this study was to optimize a simple, fast, and economical analysis procedure for the determination of 16 different pesticides in raw milk via GC/MSD. Analyses were performed via gas chromatography with electron impact mass spectrometric detection in the selected ion monitoring mode (GC/MSD-SIM) using Pentachloronitrobenzene as the internal standard. The modified sample preparation methodology was based on the Pesticide Analytical Manual (PAM) of the FDA concerning fat extraction, ACN-ether partitioning, and clean-up of the Sep-Pak florisil cartridge. The modified methodology for the determination of the 16 pesticides was validated. The range of LOQs of the 16 pesticides was likely three times lower than their Maximum Residence Levels (MRLs). The recoveries of most of the pesticides were acceptable at the fortification levels of $0.5 \mathrm{and} 1.0 \mu \mathrm{g} /$ $\mathrm{mL}$ and their RSD (\%) level was less than $20 \%$. None of the 16 pesticides were detected in the selected raw milk samples.
\end{abstract}

Key words: pesticides, raw milk, gas chromatography/mass spectrometric detection-selected ion monitoring, limit of quantification, recovery

\section{서 론}

농약은 농작물의 병해충 및 말라리아 등과 같은 전염병 의 관리를 위해 살충제 등으로 사용되어 왔으며, 대표적으 로 aldrin, dieldrin, DDT(dichloro-diphenyl-trichloroethane)와 같은 유기염소계 농약(organochlorine pesticides)이 주로 사 용되어 왔다. 특히 축산농가에서는 가축들의 체외기생충 관리를 위해 DDT, endosulfan, lindane 등과 같은 유기염 소계 농약들이 많이 사용되고 있다(Fytianos et al., 1985; Curtis, 1994). 대부분의 유기 염소계 살충제는 증기압이 낮아 매우 안정적이고, 물에 매우 낮은 용해도를 가지므 로 강한 지용성과 미생물에 의한 분해에 저항성을 나타낸 다(UNEP, 2001; Kaushik and Kaushik, 2007). 이들은 환 경이나 지방성 동물조직에 축적되어 살아있는 생물에게 1 차적으로 독성을 가하게 되며 이와 관련한 식품에서 농약 이 잔류하게 된다. 유제품에서의 농약 잔류경로는 축산농

*Corresponding author : Nam-Su OH, Institute of Dairy Food Research, Seoul Dairy Cooperative, Ansan 425-838, Korea. Tel: 82-31-491-3867, Fax: 82-31-491-9179, E-mail: ohns@ seoulmilk.co.kr
가에서 오염된 사료 및 건초를 섭취한 젖소에서 기인하는 데, 젖소의 지방성 조직에 축적된 농약은 체내에서 이동 하여 원유 중 지방성분을 통하여 배출되며 우유나 버터와 같은 유제품으로 순차적으로 오염된다(Bentabol and Jodral, 1995; Willes, 1993). 농약의 독성은 단기간의 급성독성으 로는 그 수준을 거의 인식하기 어려우며, 장기간의 섭취 로 인한 만성독성으로 나타나기 때문에 정부차원에서의 사전 관리감독이 매우 중요하다. 따라서 $\mathrm{WHO} / \mathrm{FAO}$ 에서는 최대잔류량(maximum residue level, MRL)을 설정하여 관 리하고 있으며, 국내에서도 식품위생법 제 7조에 348종의 농약에 대해 식품 중 잔류허용기준을 설정하여 관리하고 있다(WHO/FAO, 2006). 축산물 중 농약의 다성분 분석법은 미국의 FDA가 편찬한 PAM(Pesticides Analytical Manual) 과 AOAC international의 970.52 method가 대표적이며 (MacMahon et al., 1994), 국내의 정부기관 및 민간기관에 서도 이와 동등한 방법을 사용하거나 유사한 분석법을 사 용하고 있다. 그러나 PAM의 경우 식품시료내의 방해물질 을 효과적으로 제거할 수 있는 반면 시간, 용매 등이 지 나치게 사용되어야 하는 단점이 있다. 이에 본 연구에서 는 $\mathrm{GC} / \mathrm{MSD}$ 를 사용하여 매트릭스에 의한 간섭을 최소화 
하면서 효과적으로 스크리닝 할 수 있는 16 종 잔류 농약 의 동시분석 조건을 설정하고 1 회용 sep-pak cartridge를 사용함으로써 정제 과정의 시간 및 용매량을 최대한 단축 시켜 간편하고 효율적으로 사용할 수 있는 전처리 방법을 최적화하여 원유에 대한 잔류 실태를 조사하여 그 결과를 보고자 하였다.

\section{재료 및 방법}

\section{시료 및 시약}

실험에 사용한 원유는 경인지역 4곳의 목장에서 공급받 아 사용하였다. 16 종의 개별 잔류농약은 순도 $90 \%$ 이상 의 분석용 표준품을 Dr. Eherenstofer $\mathrm{GmbH}$ (Augsburg, Germany)에서 구입하여 사용하였으며, 내부표준용액인 pentachloronitrobenzene(PCNB)는 Chem sErvice Inc.(USA) 에서 구입하여 사용하였다. 그 외에 전처리 과정 및 분석에 사용된 시약은 모두 잔류분석용이나 특급시약을 사용하였다.

\section{분석 대상물질 및 내부표준물질}

분석 대상 물질은 aldrin, p,p'-DDT(dichloro-diphenyltrichloroethane), o,p'-DDT, p,p'-DDE(dichloro-diphenyl-dichloroethylene), $\alpha$-endosulfan, $\beta$-endosulfan, endosulfn sulfate, dieldrin, hepachor-epoide, chlordane, diazinon, bifenthrin, methoprene, cyfluthrin, cypermethrin, fenvalerate의 16 종 농 약으로 선정하였다(Table 1).

\section{사용기기}

Table 1. Retention times $\left(t_{\mathrm{R}}\right)$, relative retention times $\left(t_{\mathrm{RR}}\right)$ and selected ions of the studied pesticides

\begin{tabular}{|c|c|c|c|}
\hline Pesticides & $t_{\mathrm{R}}(\min )$ & $t_{\mathrm{RR}}(\min )$ & $\mathrm{m} / \mathrm{z}^{1)}$ \\
\hline $1 \mathrm{PCNB}^{2)}$ & 13.4 & 1.0 & 237,249 \\
\hline 2 Diazinon & 14.1 & 1.1 & $\underline{179}, 274,100$ \\
\hline 3 Aldrin & 17.5 & 1.3 & $\underline{263}, 66,265$ \\
\hline 4 Heptachlor epoxide & 18.9 & 1.4 & $\underline{353}, 355,351$ \\
\hline 5 Chlordane & 19.7 & 1.5 & $\underline{373}, 375,377$ \\
\hline 6 Methoprene & 19.7 & 1.5 & $\underline{73}, 111,109$ \\
\hline $7 \alpha$-endosulfan & 20.3 & 1.5 & $\underline{241}, 195,239$ \\
\hline 8 p,p'-DDE & 21.1 & 1.6 & $\underline{264}, 318,316$ \\
\hline 9 Dieldrin & 21.2 & 1.6 & $\underline{79}, 263,81$ \\
\hline $10 \beta$-endosulfan & 22.4 & 1.7 & $\underline{195}, 237,241$ \\
\hline 11 o,p'-DDT & 22.8 & 1.7 & $\underline{235}, 237,165$ \\
\hline 12 Endosulfan sulfate & 23.8 & 1.8 & $\underline{272}, 274,387$ \\
\hline 13 p,p'-DDT & 24.0 & 1.8 & $\underline{235}, 237,265$ \\
\hline 14 Bifenthrin & 25.9 & 1.9 & $\underline{181}, 166,165$ \\
\hline 15 Cyfluthrin & 31.0 & 2.2 & $163,206,165$ \\
\hline 16 Cypermethrin & 32.3 & 2.4 & $\underline{163}, 181,165$ \\
\hline 17 Fenvalerate & 35.1 & 2.6 & $\underline{125}, 167,181$ \\
\hline
\end{tabular}

${ }^{1)}$ Target ions are underlined

${ }^{2)}$ Internal standard

\section{기구}

회전감압농축기는 EYELA(Tokyo Rikakikai Co. Ltd., Japan)를 사용하고 질소농축기는 TurboVap(Zymark, USA) 을 사용하였으며, 1회용 Sep-Pak Florisil Cartridge(10 g, $35 \mathrm{cc}$, Waters, USA)는 Vacuum Manifold Assembly(Agilent, $\mathrm{USA}$ )에 장착하여 사용하였다.

\section{분석기기}

분석 대상농약을 정성 및 정량분석하기 위하여 $7890 \mathrm{~A}$ Gas Chromatograph에 5975C Mass Spectrometry(Agilent, Santa Clara, USA)를 장착한 $\mathrm{GC} / \mathrm{MSD}$ 를 사용하였다.

\section{실험방법}

\section{표준용액의 조제}

개별 농약 표준품을 $20 \%$ acetone/n-hexane에 녹여 1000 $\mu \mathrm{g} / \mathrm{mL}$ 수준의 stock solution을 조제하였다. $5000 \mu \mathrm{g} / \mathrm{mL}$ 의 원액상태인 내부표준물질(PCNB)은 표준품과 동일한 용매 를 사용하여 희석하였으며, 혼합 표준용액과 시료에 각각 동일하게 $5 \mu \mathrm{g} / \mathrm{mL}$ 이 첨가되도록 조제하였다. 혼합 표준 원액은 $10 \mu \mathrm{g} / \mathrm{mL}$ 수준으로 조제하였고, 검량곡선 작성을 위한 혼합 표준 용액은 $20 \%$ acetone/n-hexane에 희석하여 $0.05 \mu \mathrm{g} / \mathrm{mL}, 0.1 \mu \mathrm{g} / \mathrm{mL}, 0.5 \mu \mathrm{g} / \mathrm{mL}, 1 \mu \mathrm{g} / \mathrm{mL}, 2 \mu \mathrm{g} / \mathrm{mL}$ 로 조제하여 분석 전까지 $-4^{\circ} \mathrm{C}$ 에서 보관하였다.

\section{추출}

검체는 약 $50 \mathrm{~g}$ 을 정밀히 칭량하였고, 지방의 추출은 FDA PAM(MacMahon et al., 1996)의 추출방법에 따라 수 행하였다.

\section{정제}

추출된 지방을 약 $1-2 \mathrm{~g}$ 칭량하고 내부표준용액 $0.5 \mathrm{~mL}$ 을 첨가하였다. 이를 petroleum ether $15 \mathrm{~mL}$ 를 넣은 $250 \mathrm{~mL}$ 분액여두로 옮기고, petroleum ether로 포화시킨 acetonitrile $(\mathrm{ACN})$ 용액 $30 \mathrm{~mL}$ 을 넣어 1분간 진탕 추출하였다. 분리된 $\mathrm{ACN}$ 층은 증류수 $200 \mathrm{~mL}$ 및 $\mathrm{NaCl}$ 포화용액 $40 \mathrm{~mL}$ 을 넣 은 $500 \mathrm{~mL}$ 분액여두에 다시 옮겼다. $250 \mathrm{~mL}$ 분액여두에 남아있는 petroleum ether 잔류물을 같은 방법으로 3회 추 출하여 $\mathrm{ACN}$ 층을 $500 \mathrm{~mL}$ 분액여두에 모두 합친 후 petroleum ether $100 \mathrm{~mL}$ 을 넣고, 1 분간 진탕 추출하였다. 방치하여 분리된 수층은 또 다른 $500 \mathrm{~mL}$ 분액여두에 옮 기고 다시 petroleum ether $100 \mathrm{~mL}$ 을 넣어 1분간 추출한 후 분리된 petroleum ether 층을 첫 번째 $500 \mathrm{~mL}$ 분액여 두에 합하였다. Petroleum ether 층은 증류수 $100 \mathrm{~mL}$ 로 2 회 세척한 후 무수 $\mathrm{Na}_{2} \mathrm{SO}_{4}$ 를 통과시켜 탈수시키고, 이 액 을 회전감압농축기 $\left(40^{\circ} \mathrm{C}\right.$, 수욕조 $)$ 를 사용하여 약 $1 \mathrm{~mL}$ 까 지 농축하였다. 
Sep-Pak Florisil Cartridge를 petroleum ether $20 \mathrm{~mL}$ 로 활 성화한 후 사용하였다. 활성화시킨 Sep-Pak Florisil Cartridge 에 시험용액을 가한 후 $6 \%$ diethyl ether/petroleum ether, $15 \%$ diethyl ether/petroleum ether, 50\% diethyl ether/ petroleum ether를 각각 $100 \mathrm{~mL}, 50 \mathrm{~mL}, 100 \mathrm{~mL}$ 씩 차례로 용출시켰다. 용출액은 수욕조 $\left(40^{\circ} \mathrm{C}\right)$ 에서 질소가스로 농축 한 후 잔사를 $20 \%$ acetone/n-hexane으로 녹여서 전량을 5 $\mathrm{mL}$ 로 하고, 이를 $0.45 \mu \mathrm{m}$ membrane filter를 통과시켜 $\mathrm{GC} /$ $\mathrm{MSD}$ 용 시험용액으로 사용하였다.

\section{기기분석}

농약 분석을 위한 column은 J\&W Scientific(Folsom, $\mathrm{USA})$ 에서 구입한 DB5-ms(30 $\mathrm{m} \times 0.25 \mathrm{~mm} \times 0.25 \mu \mathrm{m}$ film thickness)를 사용하였다. Carrier gas는 helium을 사용하였 고, 주입량은 $1 \mu \mathrm{L}$ (split ratio 10:1), column flow rate는 0.9 $\mathrm{mL} / \mathrm{min}$, 주입부 온도는 $260^{\circ} \mathrm{C}$ 로 설정하였다. 오븐 온도는 초기온도 $80^{\circ} \mathrm{C}$ 에서 2 분 30 초간 유지하고 $140^{\circ} \mathrm{C}$ 까지 분당 $50^{\circ} \mathrm{C}$ 의 속도로 승온한 후, $260^{\circ} \mathrm{C}$ 까지 분당 $5^{\circ} \mathrm{C}$ 로 승온하 여 15 분간 등온시키는 조건을 사용하였다. $\mathrm{MSD}$ 는 ionizing energy $70 \mathrm{eV}$ 의 electron impact ionization mode(EI-mode) 를 사용하였고, source(Quad) 및 transfer line의 온도는 각 각 $150^{\circ} \mathrm{C}, 280^{\circ} \mathrm{C}$ 로 하였다. Full Scan-mode $(50-350 \mathrm{~m} / \mathrm{z})$ 를
사용하여 개별 농약의 정보를 조사하였으며, GC/MSDSIM-mode를 사용하여 정량 분석을 수행하였다.

\section{회수율 시험}

시험방법의 회수율을 확인하기 위하여 공시료에 16 종의 잔류 농약 표준물질을 첨가하여 실험하였다. 분석법의 회 수율은 $0.5 \mu \mathrm{g} / \mathrm{mL}$ 및 $1 \mu \mathrm{g} / \mathrm{mL}$ 의 처리농도에서 각각 3 반복 으로 측정하고 회수율 및 상대표준편차 $(\mathrm{RSD}, \%)$ 를 확인 하여 분석방법의 정확도 및 정밀도를 확인하였다.

\section{결과 및 고찰}

\section{기기분석 조건}

본 연구에서는 16 종의 농약을 분석하기 위하여 GC/MSD 를 사용하여, 정성 및 정량분석을 동시에 수행하고자 하 였다. 분석대상 농약 표준물질 및 내부 표준용액인 $\mathrm{PCNB}$ 혼합 표준용액의 크로마토그램은 Fig. 1과 같다. 설정된 $\mathrm{GC}$ 조건은, 오븐온도프로그램의 최종온도를 $280^{\circ} \mathrm{C}$ 이상 으로 승온시킬 경우 peak의 감도는 높아지나 baseline rising 현상이 발생하여 해당 retention time(RT) 범위에서 $1 \mu \mathrm{g} /$ $\mathrm{mL}$ 이하의 저농도일 경우 peak의 인식이 간섭을 받으므 로 정확한 분석 수행이 어려운 점을 감안하여 최종 온도

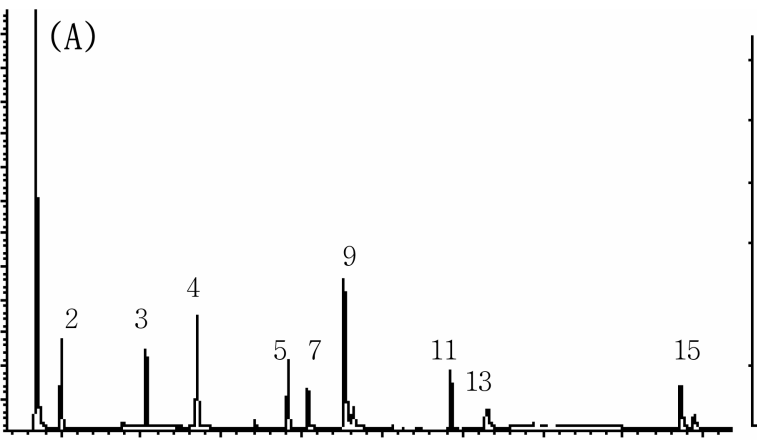

(B)

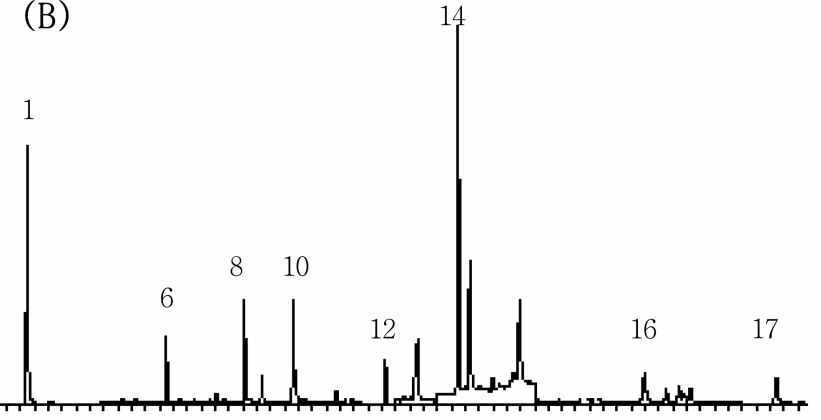

Fig. 1. GC/MS-SIM chromatogram of 16 pesticide standard solution containing $0.5 \mu \mathrm{g} / \mathrm{mL}$. See Table 1 for peak identification (A) SIM program group 1, (B) SIM program group 2.

Table 2. SIM program used to analyze 16 pesticides

\begin{tabular}{ccll}
\hline \hline Group & Time (min) & \multicolumn{1}{c}{ Pesticides } & \multicolumn{1}{c}{$\mathrm{m} / \mathrm{z}$} \\
\hline & 3.00 & PCNB $^{1)}$ & 237,249 \\
& 13.80 & Diazinon, aldrin & $179,274,100,263,66,265$ \\
1 & 18.20 & Heptachlor-epoxide & $353,355,351$ \\
& 19.30 & Chlordane, $\alpha$-endosulfan & $373,375,377,241,195,239$ \\
& 20.85 & Dieldrin, o,p'-DDT, p,p'-DDT & $79,263,81,235,237,165$ \\
& 29.00 & Cyfluthrin & $163,206,165$ \\
\hline & 3.00 & PCNB & 237,249 \\
& 18.00 & Methoprene & $73,111,109$ \\
& 20.35 & p,p'-DDE, $\beta$-endosulfan & $264,318,316,195,237,241$ \\
& 23.10 & Endosulfan sulfate & $272,274,387$ \\
& 25.10 & Bifenthrin, cypermethrin & $181,166,165,163$ \\
\end{tabular}

\footnotetext{
1) Internal standard
} 
를 $260^{\circ} \mathrm{C}$ 로 설정하였다(Campoy et al., 2001). 정성 및 정 량분석을 위해 사용된 16 종의 농약 성분들을 Full Scan$\operatorname{mode}(50-350 \mathrm{~m} / \mathrm{z})$ 로 분석하여 얻어진 RT 및 relative retemtion time(RRT)는 Table 1 과 같다. 정량분석은 선택이온 검 색법(selected ion monitoring, SIM)을 사용하여 분석하였 으며, SIM-mode의 사용을 위한 분석조건은 두 group으로 나누어 설정하였다(Table 2). 검량선 작성을 위한 표준물 질은 본 연구에서 선정된 대상물질의 잔류기준 범위를 고 려하여 $0.05-2 \mu \mathrm{g} / \mathrm{mL}$ 농도범위에서 측정, 분석한 결과 상 관계수 $\mathrm{r}^{2}$ 은 0.9984-0.9997로서 정량분석 수행에 충분한 수 준이었다. 대상물질을 포함하고 있지 않은 공시료에 표준 물질을 첨가하여 시료 전처리법으로 정량분석을 시험한 결과 설정된 검출한계 및 정량한계는 Table 3 과 같다. 식 품위생법상의 해당 농약의 잔류기준과 비교하여 3 배 이 상 낮게 설정되어 만족하는 수준이었으며, $\mathrm{GC} / \mathrm{MSD}$ 를 사 용한 Waliaszewski와 Waliaszewski(1997)의 연구 결과와 비교하여 검출한계는 약 10 배정도 높은 수준이었으며, Consuelo 등(2008)의 연구결과보다는 10 배 이상 낮은 수 준의 정량한계가 설정되었다.

\section{회수율시험}

공시료에 표준물질을 첨가하여 3 회 반복실험을 수행하 여 회수율을 측정한 결과는 Table 4 와 같다. $0.5 \mu \mathrm{g} / \mathrm{mL}$ 처 리농도의 16 종 대상 농약성분에 대한 평균회수율은 $91.3 \%$ (62.2-124.4\%)으로 나타났으며, RSD는 7.3\%(1.5-16.9\%)으 로 확인되었다. $1.0 \mu \mathrm{g} / \mathrm{mL}$ 처리농도의 평균회수율은 $96.0 \%$ (70.3-118.0\%)였으며, RSD는 5.3\%(1.2-9.6\%)로 나타났다. 일반적으로 European Union(2007) 등의 guidance에서는 잔

Table 3. Limit of detection (LOD), limit of quantification (LOQ) and maximum residue level (MRL) of pesticides

\begin{tabular}{|c|c|c|c|}
\hline Pesticides & $\begin{array}{c}\text { LOD } \\
(\mu \mathrm{g} / \mathrm{mL})\end{array}$ & $\begin{array}{c}\text { LOQ } \\
(\mu \mathrm{g} / \mathrm{mL})\end{array}$ & $\begin{array}{c}\text { MRL } \\
(\mu \mathrm{g} / \mathrm{mL})\end{array}$ \\
\hline Diazinon & 0.01 & 0.03 & 0.5 \\
\hline Aldrin & 0.01 & 0.04 & 0.15 \\
\hline Heptachlor epoxide & 0.01 & 0.03 & 0.15 \\
\hline Chlordane & 0.01 & 0.02 & 0.25 \\
\hline Methoprene & 0.01 & 0.03 & 1.25 \\
\hline$\alpha$-endosulfan & 0.01 & 0.04 & 0.1 \\
\hline p,p'-DDE & 0.01 & 0.02 & 0.5 \\
\hline Dieldrin & 0.01 & 0.04 & 0.15 \\
\hline$\beta$-endosulfan & 0.01 & 0.04 & 0.1 \\
\hline o,p'-DDT & 0.01 & 0.03 & 0.5 \\
\hline Endosulfan sulfate & 0.01 & 0.03 & 0.1 \\
\hline p,p'-DDT & 0.01 & 0.04 & 0.5 \\
\hline Bifenthrin & 0.04 & 0.1 & 0.25 \\
\hline Fenpropathrin & 0.01 & 0.03 & 2.5 \\
\hline Cyfluthrin & 0.04 & 0.1 & 0.25 \\
\hline Fenvalerate & 0.01 & 0.03 & 2.5 \\
\hline
\end{tabular}

Table 4. Average \% recoveries and \% RSD of pesticides in raw milk

\begin{tabular}{|c|c|c|c|c|}
\hline \multirow[b]{2}{*}{ Pesticides } & \multicolumn{2}{|c|}{ Spiked $0.5 \mu \mathrm{g} / \mathrm{mL}$} & \multicolumn{2}{|c|}{ Spiked $1.0 \mu \mathrm{g} / \mathrm{mL}$} \\
\hline & $\begin{array}{c}\text { Recovery } \\
(\%)^{1)}\end{array}$ & $\begin{array}{l}\text { RSD } \\
(\%)^{2)}\end{array}$ & $\begin{array}{c}\text { Recovery } \\
(\%)^{1)}\end{array}$ & $\begin{array}{l}\text { RSD } \\
(\%)^{2)}\end{array}$ \\
\hline Diazinon & $88.9 \pm 5.9$ & 6.6 & $94.3 \pm 8.1$ & 8.6 \\
\hline Aldrin & $110.0 \pm 4.7$ & 4.3 & $104.5 \pm 3.5$ & 3.4 \\
\hline $\begin{array}{l}\text { Heptachlor } \\
\text { epoxide }\end{array}$ & $97.0 \pm 16.4$ & 16.9 & $94.3 \pm 2.1$ & 2.3 \\
\hline Chlordane & $101.5 \pm 12.6$ & 12.5 & $99.5 \pm 8.4$ & 8.5 \\
\hline Methoprene & $100.7 \pm 3.4$ & 3.4 & $111.0 \pm 8.0$ & 1.3 \\
\hline$\alpha$-endosulfan & $102.2 \pm 9.4$ & 9.2 & $106.0 \pm 1.4$ & 1.3 \\
\hline $\mathrm{p}, \mathrm{p}^{\prime}-\mathrm{DDE}$ & $85.2 \pm 5.6$ & 6.6 & $85.0 \pm 3.0$ & 3.5 \\
\hline Dieldrin & $62.2 \pm 2.2$ & 3.6 & $70.3 \pm 4.9$ & 7.0 \\
\hline$\beta$-endosulfan & $85.9 \pm 1.3$ & 1.5 & $86.0 \pm 1.0$ & 1.2 \\
\hline o,p'-DDT & $85.2 \pm 5.6$ & 6.6 & $89.0 \pm 6.3$ & 7.0 \\
\hline Endosulfan sulfate & $70.1 \pm 1.6$ & 2.2 & $85.7 \pm 3.5$ & 4.1 \\
\hline $\mathrm{p}, \mathrm{p}$ '-DDT & $69.6 \pm 9.3$ & 13.3 & $79.3 \pm 6.1$ & 7.7 \\
\hline Bifenthrin & $96.3 \pm 7.8$ & 8.1 & $107.0 \pm 5.6$ & 5.2 \\
\hline Cyfluthrin & $82.2 \pm 8.0$ & 9.7 & $88.3 \pm 6.7$ & 7.5 \\
\hline Cypermethrin & $118.5 \pm 5.1$ & 4.3 & $117.3 \pm 7.4$ & 6.3 \\
\hline Fenvalerate & $124.4 \pm 9.7$ & 7.8 & $118.0 \pm 11.4$ & 9.6 \\
\hline
\end{tabular}

류농약 분석 측정값의 허용 회수율 범위는 70-120\%이며, $\mathrm{RSD}$ 는 $20 \%$ 이내로 권장기준을 제시하고 있다. 본 연구 에서 수행된 회수율 시험 결과 대부분의 농약성분이 적정 범위를 충족하고 있으나, $0.5 \mu \mathrm{g} / \mathrm{mL}$ 처리농도의 회수율 시 험 중 Dieldrin, p,p'-DDT, fenvalerate 등의 일부 농약성분 들은 권장기준에 다소 벗어난 값을 나타내었다. USDA 등 의 일부 method validation guideline(2002)에서는 허용 회 수율 범위를 50-150\%로 확대하여 제시하고 있으며, 확대 된 회수율 범위에는 모든 농약성분들이 적합한 회수율을 나타내어 비교적 만족할 만한 결과를 나타낸 것으로 사료 되었다. $\mathrm{RSD}$ 의 경우 각각의 처리농도에서 모든 농약성분 이 $20 \%$ 이내로 적합한 정밀성을 나타내었다.

\section{원유 중 잔류 농약 분석}

이와 같이 최적화된 분석방법을 수급되는 원유 중 농약 잔류를 검사하기 위하여 경인지역 목장 중 4곳에서 공급 받은 원유 실제시료 분석에 적용하였다. 분석의 정확성을 높이기 위하여 실제시료에 quality control $(\mathrm{QC})$ 시료를 포함 한 그룹을 만들어 분석하였다. 분석 결과 대상 시료인 원 유 4품목에서 분석대상성분이 검출되지 않았다. 연구결과 에서 보는 바와 같이 설정된 방법을 향후 우유 및 기타 유제품의 분석에도 적용하여 이용할 수 있을 것으로 판단 된다. 


\section{결 론}

본 연구에서는 $\mathrm{GC} / \mathrm{MSD}$ 를 사용한 원유에서의 16 종 잔 류농약의 동시분석을 위한 최적화된 $\mathrm{GC} / \mathrm{MSD}$ 의 분석 조 건을 설정하였으며, $\mathrm{MSD}$ 는 $\mathrm{EI}-$ mode를 사용하여 선택이 온 검색법(selected ion monitoring, SIM)으로 정량 하였다. 대상 농약성분 분석을 위한 전처리는 $\mathrm{PAM}$ 을 변형하여 용 매량 및 시간을 단축시켜 신속하고 효율적인 방법을 설정 하고자 하였다. 설정된 분석법의 신뢰성을 확보하기 위한 유효성의 검토는 개별 농약성분의 $\mathrm{LOD}$ 와 $\mathrm{LOQ}$ 를 설정하 여 각 $\mathrm{MRL}$ 과 비교 확인하였으며, 공시료에 표준물질을 첨가하여 회수율 및 재현성을 확인하였다. 설정된 $\mathrm{LOQ}$ 는 해당 농약 성분의 MRL과 비교하여 약 3 배 이상의 수준 으로 낮게 설정되었다. $0.5 \mu \mathrm{g} / \mathrm{mL}$ 및 $1 \mu \mathrm{g} / \mathrm{mL}$ 의 처리농도 에서 16 종 대상 농약성분에 대한 평균회수율은 각각 $91.3 \%$ 및 $96.0 \%$ 였으며, 평균 $\mathrm{RSD}$ 는 각각 $7.3 \%, 5.3 \%$ 로 나타났 다. 따라서 본 연구에서 설정된 분석법은 반복 분석을 통 한 유효성의 검토 결과 시험의 정확도 및 재현성이 만족 하는 수준인 것으로 사료되며, 향후 우유 및 기타 유제품 의 분석에도 적용하여 활용 가능성이 높을 것으로 기대된다.

\section{참고문헌}

1. Agricultural Marketing Service (2002) Acceptability Criteria of Process Control and Foltification Recoveries, PDP-QC04, US. Dept. of Agriculture, Manassas, VA.

2. Bentabol, A. and Jodral, M. (1995) Occurrence of organochlorine agrochemical residues in Spanish cheese. Pestic. Sci. 44, 177-182.

3. Campoy, C., Jimemz, M., Olea, S., Moreno, M., Canabate, F., Olea, N., Bayes, R., and Molina-Font, J. A. (2001) Analysis of organochlorine pesticides in human milk: preliminary results. Early Human Devel. 65, S183-S190.

4. Consuelo, S. B., Esther, M., and Jose, L. T. (2008) Determination of organochroline pesticides in sewage sludge by matrix solid-phase dispersion and gas chromatography-mass spectrometry. Talanta 74, 1211-1217.

5. Curtis, C. F. (1994) Should DDT continue to be recommended for malaria vector control? Med. Vet. Entomol. 101, 378-384.

6. European Union (2007) Method Validation and Quality Control Procedures for Pesticide Residues Analysis in Food and Feed (Document No. SANCO/10232/2006). Available from : http://ec.europa.eu/food/plant/protection/resources/ qualcontrol_en.pdf

7. Fytianos, K., Vasilikiotis, G., Weil, L., Kavlendis, E., and Laskaridis, N. (1985) Preliminary study of organochroline compounds in milk products, human milk and vegetables. Bull. Environ. Contam. Toxicol. 34, 504-508

8. Kaushik, P. and Kaushik, G. (2007) An assessment of structure and toxicity correlation in organochlorine pesticides. $J$. Hazard Mater. 143, 102-111.

9. McMahon, B., Wagner, M., and Roberta, F. (1996) Pesticide Analytical Manual Volume 1, 3rd ed. US FDA, Washington, DC.

10. UNEP (2001) Act of the Conference of Plenipotentiaries on the Stockholm Convention on Persistent Organic pollutants, United Nations Environment Programme, Stockholm, Sweden.

11. Waliszewski, S. M. and Waliszewski, J. M. (1997) Organochlorine pesticides residues in cow' milk and butter in Mexico. J. Sci. Total Environ. 208, 127-132

12. WHO/FAO (2006) Maximum residue limits for pesticides and veterinary drugs. Food and Agricultural Organization of the United Nation (FAO), World Health Organization (WHO), Rome. Available from : http://www.fao.org/ag/AGP/AGPP/ Pesticid/JMPR/DOWNLOAD/bilthoven2005.pdf.

13. Willes, R. F., Nestman, E. R., and Miller, P. A. (1993) Scientific principles for evaluating the potential for adverse effects from chlorinated organic chemicals in the environment. Regul. Toxicol. Pharmacol. 18, 313-356.

(Received 2008.9.23/Revised 1st 2009.3.2, 2nd 2009.6.19/ Accepted 2009.7.16) 